\title{
CORPO E CLASSIFICADORES NAS LÍNGUAS DE SINAIS
}

\author{
BODY AND CLASSIFIERS IN SIGN LANGUAGES
}

\section{CUERPO Y CLASIFICADORES EN LAS LENGUAS DE SEÑAS}

Bruno Gonçalves Carneiro*

\begin{abstract}
Resumo
O objetivo deste artigo é discutir os predicados classificadores na língua de sinais brasileira considerando a língua um sistema simbólico atrelado a processos cognitivos gerais e à nossa experiência corporal diária. Nesta perspectiva, vimos que o sinalizante cede seu corpo de forma a elaborar uma codificação transparente daquilo que é concebido pelo corpo. As ações de ver, verificar, correr, remar, lançar e colocar, por exemplo, identificadas em nossa análise, refletem as ações que experienciamos na relação com o mundo. Percebemos os classificadores como uma mimese corporal elaborada, o que não elimina a presença de elementos lexicalizados.
\end{abstract}

Palavras-chave: classificadores, língua de sinais, experiência corporal, iconicidade.

De acordo com Leite (2008), houve um período recente em que linguistas precisavam comprovar, nas línguas de sinais, todas as teorias aplicadas às línguas orais, numa tentativa de demonstrar que essas eram, de fato, naturais. Atualmente, apesar de ainda lidar com tais situações, mas num sinal de amadurecimento da área, pesquisas nesse campo buscam salientar justamente as especificidades das línguas sinalizadas, o que permite uma reconsideração de aspectos das próprias línguas orais. Itens que antes eram observados como característicos às línguas de sinais contemplam níveis de análise que foram ignorados nos estudos linguísticos.

O resultado inicial desta busca pela descrição das línguas de sinais a partir do modelo previsto para as línguas orais foi a obtenção de conclusões que descreviam e/ou apontavam o que "faltava" a essas línguas, ou seja, às línguas de sinais foram atribuídas carências de

\footnotetext{
* Mestre em Letras e Linguística pela Universidade Federal de Goiás. Professor Assistente da Universidade Federal do Tocantins, Campus de Porto Nacional, no colegiado do curso Letras Libras Licenciatura. Atua em descrição e análise da língua de sinais brasileira e educação de surdos. E-mail: brunocarneiro@uft.edu.br
} 
artigos e de preposições, de marcadores de número e gênero, bem como de processos morfológicos de tempo e modo verbal. Posteriormente, ao haver uma maior aceitação das línguas de sinais, suas especificidades gramaticais passaram a ser descritas e respeitadas (LODI, 2004, p. 286).

Sem a tentativa de traçar fortes paralelos entre as línguas sinalizadas e faladas ${ }^{1}$, não se admitiriam (ainda em 1960), pesquisas sobre a língua de sinais americana como campo legítimo dentro dos estudos linguísticos (LIDDELL, 2003a). Sabemos ser ampla a manifestação de como os aspectos funcionais das línguas se materializam e, certamente, há padrões tipológicos específicos a cada modalidade. Daí a necessidade de "olhar as línguas de sinais a partir delas mesmas enquanto línguas visuais-espaciais" (QUADROS, 2006, p. 169). De acordo com Meier (2002, p. 5), “podemos ficar seguros quanto ao entendimento de que a discussão sobre as diferenças de modalidade não ameaçam a fundamental conclusão de que as línguas de sinais são, de fato, línguas”.

Devido ao império do postulado da arbitrariedade/não motivação do signo linguístico (SAUSSURE, 1959 [1916]), muitos mitos e preconceitos foram gerados em relação às línguas de sinais, rebaixando-as a representações miméticas, encenações e, quando admitidas como sistemáticas, incapazes de expressar ideias abstratas (TAUB, 2001). Outra grave consequência foi a atenuação da importância do caráter icônico e do papel desempenhado pelos gestos na organização das línguas de sinais (BOLGUERONI; VIOTTI, 2013; LEITE, 2008; LIDDELL, 2003a; MCCLEARY; VIOTTI, 2011), o que provavelmente originou a suposição inicial de que toda fonte de significado nas línguas de sinais provinha de morfemas (LIDDELL, 2003a).

Segundo Duncan (2003) e Schembri (2003), os estudos sobre línguas sinalizadas são recentes e a emergência repentina de pesquisas nessa área da linguística, criou a necessidade urgente de nomear fenômenos que eram observados durante a descrição das línguas de sinais. O mais adequado, naquele momento, foi lançar mão de termos já usados na descrição das línguas orais. E, de acordo com os autores, este parece ser o caso dos classificadores.

O objetivo deste artigo é discutir os predicados classificadores na língua de sinais brasileira visualizando o corpo do sinalizante numa perspectiva mais ampla, vinculado a processos cognitivos gerais e atrelado à experiência corporal diária. Para isso, dois textos em Libras, sinalizados por surdos adultos, foram analisados com o auxílio do Elan. 


\section{Linguística cognitiva e as línguas de sinais}

A língua é um fenômeno que nos permite apreender o mundo, um sistema simbólico atrelado a processos cognitivos gerais e à nossa experiência corporal diária, pelo qual concebemos e codificamos os acontecimentos da realidade objetiva. É nesse conjunto de percepções e sensações mais elementares que realizamos novas concepções e projetamos estruturas imaginativas a fim de entendermos situações mais elaboradas e abstratas. Assim, o corpo é fundamental na concepção do mundo (JOHNSON, 1992; LANGACKER, 2008).

As línguas de sinais explicitam essa relação direta entre corpo, realidade objetiva e o sistema linguístico, devido a sua natureza articulatória manual-corporal-espacial. Isso possibilita ao corpo do sinalizante codificar concepções diversas e participar da construção de estruturas icônicas, capazes de transmitir grande número de informações de maneira simultânea.

Kendon (2000) menciona que gestos manuais criam e estendem o significado, permitem a exibição de aspectos pragmáticos do enunciado e reduzem ambiguidades através da representação visual do contexto. Consoante, em relação às línguas sinalizadas, vários autores defendem ser impossível destituir da análise descritiva a "encenação" e "mimese" feita pelo sinalizante, os aspectos gradientes da posição das mãos, orientação da palma, corpo, cabeça e direção do olhar no espaço de sinalização (DUNCAN，2003; MCCLEARY; LIDDELL，2003a，2003b; OKRENT，2002; SCHEMBRI, 2003).

Ressaltamos, também, a grande simbiose entre gesto e língua responsável pela organização do discurso, pela gramática e pela construção de significação nas línguas de sinais, que vem sendo apontada por vários trabalhos recentes da linguística das línguas sinalizadas (BOLGUERONI; VIOTTI, 2013, p. 20).

Segundo Okrent (2002) e Duncan (2003), os gestos nas línguas sinalizadas são: intercalados à produção discursiva, promovendo interrupção do fluxo dos sinais; produzidos por outros articuladores que não estejam atuando na codificação do discurso propriamente dito, ou seja, produzidos pelo corpo e/ ou face simultaneamente aos sinais manuais, ou pela mão não ativa (que está livre) em relação à ativa (mão que está articulando o sinal). E também gestos que co-ocorrem simultaneamente aos sinais 
manuais, ou seja, no mesmo articulador. Exemplos ilustrativos seriam aspectos prosódicos nas línguas de sinais, como padrões afetivos na Libras.

Nas línguas sinalizadas, a criatividade parece estar, sobretudo, na utilização de diversas combinações, em diferentes graus, de partes linguísticas e partes gestuais para a criação de novas expressões, para a adição de qualificações às expressões, para a indicação do ponto de vista e afeto do sinalizador em relação aos referentes das expressões, para a descrição de lugares, objetos ou movimentos, para a narração de eventos e para a explicação de ideias. (MCCLEARY; VIOTTI, 2011, p. 291).

Além disso, Liddell (1996, 2000, 20003a) analisa muitos aspectos das línguas sinalizadas considerando a presença de Espaços Mentais (EM) e Mesclagens (EMm), envolvendo o corpo do sinalizante (Espaço sub-rogado) ${ }^{2}$. Toda produção gestual do sinalizante, nesta construção, será atribuída à entidade sub-rogada. No Espaço subrogado,

[...] algumas partes do corpo do sinalizante vão se integrar conceitualmente com participantes do espaço do evento para representar seus atos, seus pensamentos e suas vozes. Por meio da integração conceitual, o corpo do sinalizador, ou uma parte dele, se torna, então, um sub- rogado de alguém ou de alguma coisa do espaço do evento. Sub-rogados podem ser visíveis, manifestados por parte do corpo do sinalizante, ou podem ser invisíveis. Nesse caso, sabe-se de sua existência conceitual pelo fato de que certos sinais podem ser direcionados a eles. Na condição de sub-rogado, o sinalizante pode usar expressões faciais e gestos, e pode fazer demonstrações mímicas para representar um determinado evento. É importante observar que essas demonstrações não são uma cópia direta das ações dos personagens de uma história, mas a maneira como foram conceitualizadas (e reconstruídas) pelo narrador (MCCLEARY; VIOTTI, 2011, p. 298).

Não apenas em línguas sinalizadas o corpo pode ser contraparte na construção de sub-rogados. Os exemplos a seguir ${ }^{3}$, Figura 1 e Figura 2, ilustram também o uso do corpo por uma falante de língua oral, quando explica como escalou o Monte Kilimanjaro. Simultaneamente à fala, ela utiliza gestos para caracterizar o evento. As mãos são contraparte para a formação da Mesclagem: a esquerda é associada ao terreno íngreme da montanha e a direita, com o dedo indicador estendido, movimenta-se em zigue-zague de modo a representar a trajetória de deslocamento da equipe que realizava a empreitada. 
Figura 1 - Gestos associados à fala: “Aquela beira do Kilimanjaro é assim, 45 graus”.

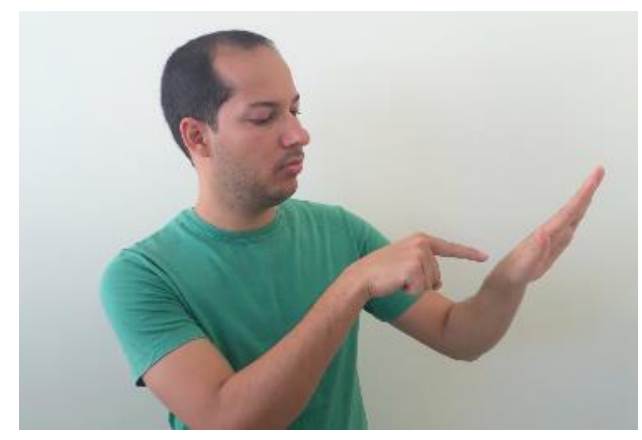

Figura 2 - Gestos associados à fala: “Aí você vai subindo, fazendo assim. Subindo, subindo, subindo".

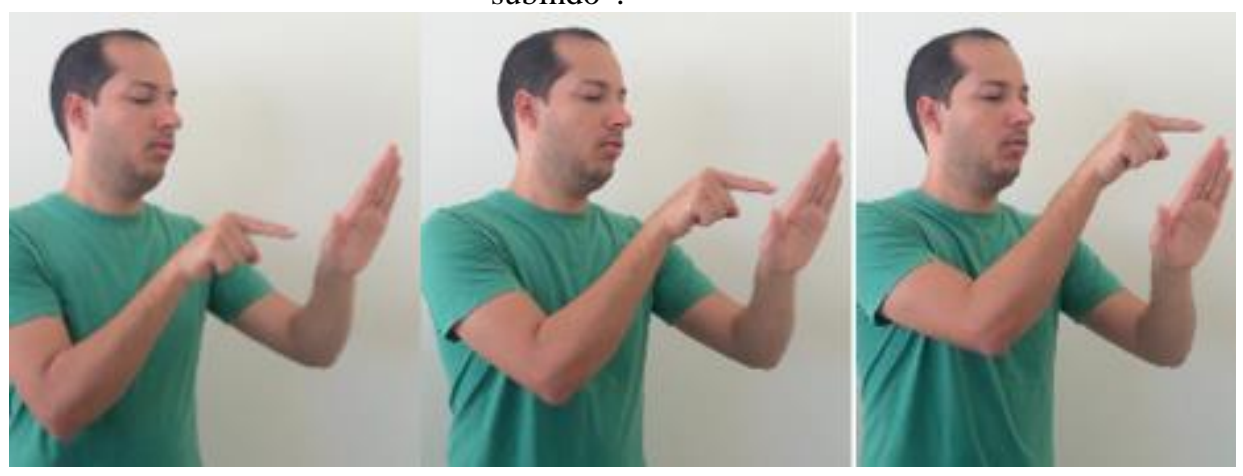

Os gestos não podem ser vistos a partir de uma ação física, mas de uma noção semiótica, já que expressam o lado imagético do pensamento durante o discurso. Gestos são gradientes, não categóricos, fazem parte da linguagem humana e do processo de produção das línguas naturais. São abundantes e onipresentes através das culturas e das línguas. Assim, a ação gestual pode ser considerada um universal linguístico (DUNCAN, 2003).

\section{Classificadores nas línguas de sinais}

Numa visão tradicional e categórica, os classificadores são sinais polimorfêmicos, estruturas icônicas em que cada aspecto formacional é um morfema classificador, dentre eles: a configuração de mão, o movimento realizado pela mão, característica do movimento, ponto inicial e final do movimento, orientação da palma, disposição do corpo do sinalizante e a disposição de parte do corpo do sinalizante. Cada parâmetro, dispondo de traços, caracterizaria um grupo de referentes. Essa perspectiva de análise considera que toda fonte de significado nas línguas de sinais provém de morfemas (LIDDELL, 2003a, 2003b). 
Pudans-Smith (2011) discute sobre terminologias usadas em estruturas em que o corpo do sinalizante participa de Mesclagens. Para o autor, o termo CLASSIFICADOR se detém a especificar as configurações de mãos e outros parâmetros formacionais, enquanto que REPRESENTAÇÃO ${ }^{4}$ abarca o fenômeno de um ponto de vista semântico, envolvendo a mimese de ações, estado e a construção de diálogos.

Apresentamos, a seguir, exemplos ${ }^{5}$ de classificadores encontrados em nosso corpus de análise. Identificamos essas construções seguindo a terminologia de Liddell (2003a), que parece nomear essas construções de verbos descritivos, pois além de codificar significados como quaisquer outros verbos, descrevem também certos aspectos da concepção. Grosso modo, os verbos descritivos codificam ações através do corpo do sinalizante, a presença e movimento de entidades no espaço, e forma e extensão de superfícies.

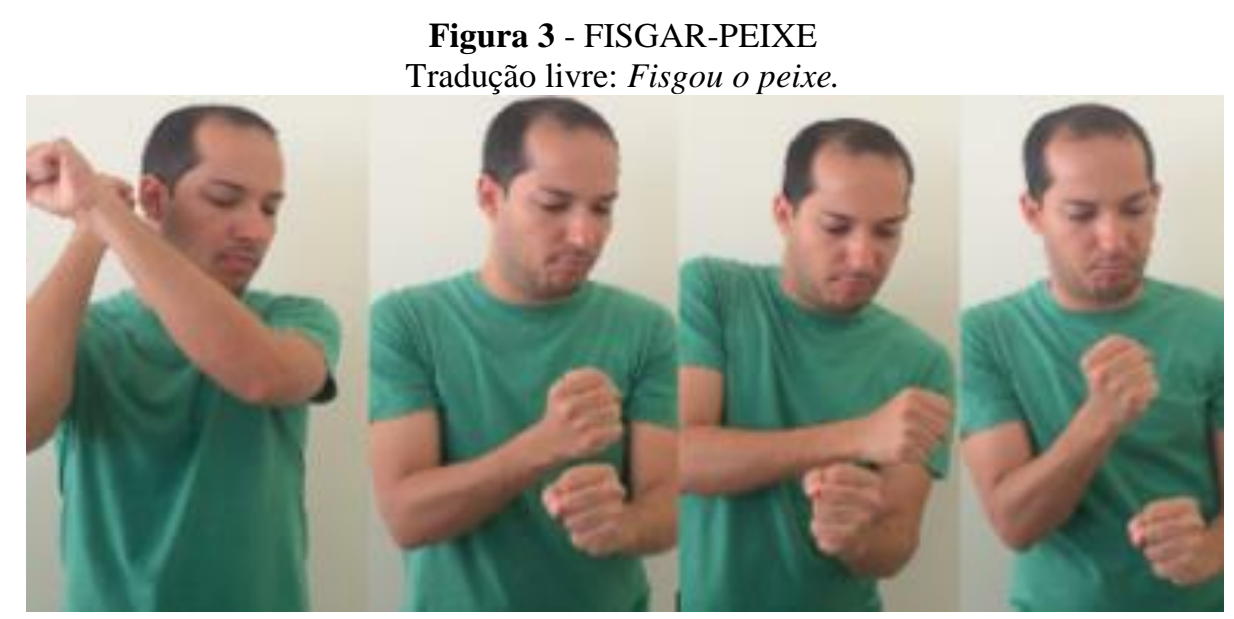

Figura 4 - BONITO PESSOA - ANDAR Tradução livre: Uma modelo bonita desfilando.

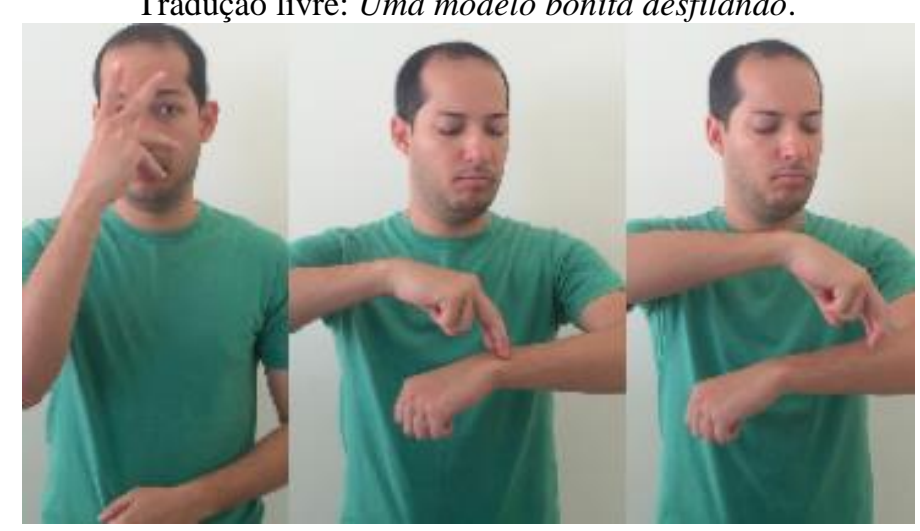


Figura 5 - ÁGUA SURPEFÍCIE DA ÁGUA (LAGO)

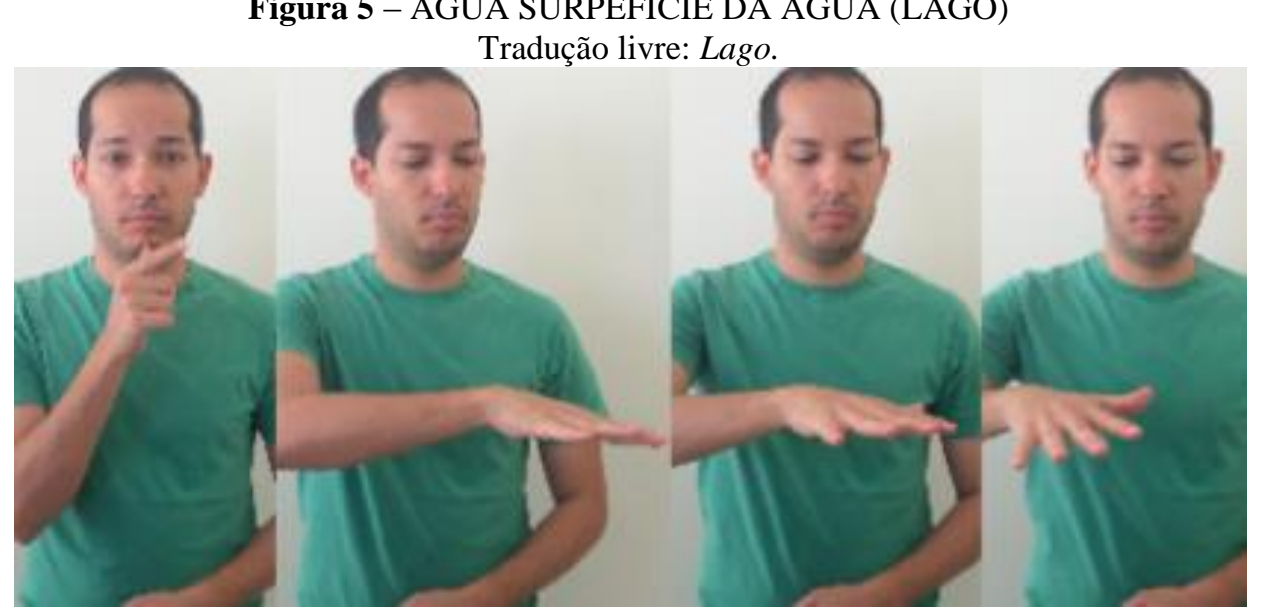

Impossível negar a iconicidade proveniente desses aspectos formacionais. Alguns autores têm sugerido que nessas construções, o uso do espaço de sinalização seria baseado na atuação de gestos associados a alguma forma lexicalizada. O deslocamento da mão e do corpo no espaço seriam movimentos miméticos, representando a disposição, o movimento e ações de referentes no espaço conceitual (FELIPE, 2006; LIDDELL, 2003a, 2003b; MCCLEARY; VIOTTI, 2011; SCHEMBRI, 2003; SCHEMBRI; et al, 2005). De acordo com Liddell (2003a, 2003b), esse comportamento em verbos descritivos segue o mesmo princípio do deslocamento das mãos nos sinais de apontar e verbos de indicação, já que esses locais apresentam um comportamento gradiente.

Ainda segundo Liddell (2003a, 2003b), os considerados morfemas classificadores não permitem a criação de paradigmas a fim de que possa ser criado um sistema morfológico discreto e recombinativo. Liddell (2003b) tem demonstrado ser improvável que todos os aspectos significativos dessas construções sejam apenas morfemas. Para o autor, essas construções parecem depender da experiência corporal. Parece ser necessário que o sinalizante experiencie a situação para que faça uma analogia aproximada do processo conceitual que é descrito.

A localização, movimento e orientação das mãos são aspectos gradientes porque o sinalizante as posiciona dentro de uma concepção mapeada no espaço físico imediato, o que promove a criação de Espaços Mentais de Mesclagem. Assim, na figura 3, as ações do sinalizante são associadas às ações de um $\mid$ agente $\left.\right|^{6}$, segurando uma $\mid$ lança $\mid$, nas margens de um $\mid$ lago|; na figura 4, o deslocamento da mão se refere ao deslocamento de uma $\mid$ modelo $\mid$ sobre uma $\mid$ passarela $\mid$; e o movimento e orientação adotados pela mão, na figura 5, margeiam o contorno da superfície das águas de um |lago|. 
Como dito anteriormente, o sistema articulatório manual-corporal-espacial das línguas de sinais é vantajoso em codificar de maneira transparente, características do processo de concepção. Muitos sinais consistem basicamente da apontação a um local específico. É o caso daqueles que indicam partes do corpo, em que o sinalizante os realiza através da apontação ao próprio corpo (indicando regiões como nariz, orelha e outras) e sinais que promovem referência no espaço de sinalização. Algumas configurações de mão e braço, bem como o deslocamento das mãos, criam uma imagem icônica do referente conceitualizado.

De forma semelhante, a posição e movimento desses articuladores no espaço de sinalização podem representar a posição e o movimento de referentes, em local e de forma específica no espaço conceitual sobreposto ao espaço físico imediato. Partes do corpo do sinalizante podem representar partes do corpo de outras entidades. A mesma analogia ocorre na codificação de ações, em que movimentos e posições específicas adotadas pelo sinalizante representam movimentos e posições de uma entidade particular (TAUB, 2001). A fonte de iconicidade na maioria das línguas de sinais valese, sendo assim,

[...] da nossa percepção das mãos, braços, e dedos como possuindo formas globais, localização e movimento; em nossa capacidade de "ver" a trajetória que um objeto estabelece no espaço; em nosso conhecimento de que o corpo do sinalizante é um corpo humano, como outros corpos humanos na forma e função; no nosso conhecimento adicional que os corpos dos animais muitas vezes se assemelham a corpos humanos na forma e função; em nossa capacidade de reconhecer os movimentos do corpo que estão em determinadas atividades; em nossa percepção de que gestos corporais ocorrem ao longo do tempo e no espaço; e em nosso conhecimento dos movimentos de sinalização em si (TAUB, 2001, p. 67).

Liddell (2003a) não descarta a possibilidade de que alguns significados nessas construções venham de morfemas como unidades lexicais amplas, semelhantemente aos classificadores em línguas faladas, mas associados a Espaços Mentais, o que motiva a forma variável e gradiente da posição das mãos no espaço de sinalização.

Convergente com as colocações de Liddell (2003a, 2003b), Schembri et al (2005) apresentam os resultados de uma comparação entre as construções classificadoras realizadas por sinalizantes da língua de sinais australiana, tailandesa e gestos de ouvintes não sinalizantes, através de uma bateria de testes eliciados a partir de histórias em vídeo. O estudo caracterizou os traços de configuração, modo e trajetória 
de movimento e localização das mãos. Nos resultados da pesquisa, as configurações de mão exibiram poucas similaridades entre os grupos.

Ainda sobre essa questão, sinalizantes produziram uma menor variação de configuração de mão por categoria de referentes em relação aos não sinalizadores. Segundo os autores, a escolha das configurações pelos sinalizantes está relacionada a grupos específicos de referentes, dentro de uma categoria maior, ao invés de tentar representar características específicas de um único referente. Houve grande similaridade na representação de movimento e localização das mãos entre sinais classificadores e gestos. A similaridade entre não sinalizantes e sinalizantes na representação de movimento e relação espacial corrobora a idéia de que as línguas sinalizadas partilham algumas propriedades gestuais.

\title{
Considerações finais
}

A partir dos dados, vimos que o sinalizante cede seu corpo de forma a elaborar uma codificação transparente, através do corpo, daquilo que é concebido pelo corpo. As ações de ver, verificar, correr, remar, lançar e colocar, identificadas em nossa análise como classificadores, refletem as ações que experienciamos na relação com o mundo.

As construções classificadoras nas línguas de sinais podem ser analisadas como uma combinação de elementos linguísticos e gestuais. Segundo Mccleary e Viotti (2011, p. 302), essa "parceria entre componentes gestuais, analógicos, idiossincráticos, de um lado, e componentes linguísticos, discretos, convencionados, de outro, opera em todos os níveis, em estreita colaboração para criar textos sofisticados e informativos".

Certamente, ainda segundo os autores, a ação gestual nas línguas de sinais parece acontecer de forma sistematizada, bem mais articulada e controlada que nas línguas orais. Resta agora à linguística das línguas sinalizadas desvendar a regularidade do uso da gestualidade.

\begin{abstract}
The goal of this article is to discuss the classifier predicates in Brazilian Sign Language considering the language as a symbolic system linked to general cognitive principles and to our daily bodily experience. In this perspective, we saw that the signaler offers his body in order to create a transparent encoding of what is conceived by the body. The actions of seeing, checking, running, rowing, launching and placing, for example,
\end{abstract}


identified in our analysis, reflect the actions we experience in our relationship with the world. The classifiers are perceived as elaborate body mimesis, which does not eliminate the presence of lexicalized elements.

Key-words: classifiers, sign language, bodily experience, iconicity

\section{Resumen}

El objetivo de este artículo es discutir los atributos de los clasificadores en la lengua de señas brasileña llevando en cuenta la lengua como un sistema simbólico vinculado a procesos cognitivos generales y a nuestra experiencia corporal diaria. En esta perspectiva, hemos visto que el señalizador cede su cuerpo de manera a elaborar una codificación transparente de aquello que es concebido por el cuerpo. Las acciones de ver, verificar, correr, remar, lanzar y colocar, por ejemplo, identificadas en nuestro análisis, reflejan las acciones que experimentamos en la relación con el mundo. Percibimos los clasificadores como una mimesis corporal elaborada, lo que no elimina la presencia de elementos lexicalizados.

Palabras clave: clasificadores, lengua de señas, experiencia corporal, iconicidad.

\section{Notas}

1. O termo "línguas faladas" equivale a "línguas orais". Em alguns momentos optamos pelo primeiro em oposição a "línguas sinalizadas", por preservar as especificidades provenientes de cada modalidade.

2. Para mais detalhes sobre a Teoria dos Espaços Mentais de Tuner e Fauconnier e sua implicação nas línguas de sinais, ver Liddell (2003a).

3. Os exemplos foram originados de uma entrevista realizada por uma jornalista (participante convidada) em um programa de auditório. As imagens são ilustradas por um sinalizante alheio, para fins de publicação. Disponível em: 〈http://www.youtube.com/watch?v=6XpQ9ccSoyw> Acesso em: 11 de jul. 2011.

4. Depicting.

5. Os exemplos ora ilustrados são sinalizados por um ator alheio, para fins de publicação.

6. Notamos entre barras e em itálico, o produto da Mesclagem entre Espaços Mentais, seguindo a proposta de Liddell (2003a).

\section{Referências}

BOLGUERONI, T.; VIOTTI, E. Referência nominal em língua de sinais brasileira (Libras). Todas as letras, v. 15, n. 1, p. 17-50, 2013.

DUNCAN, S. Gesture in language: issues for sign language research. In: EMMOREY, $\mathrm{K}$ (Ed.). Perspectives on classifier constructions in sign languages. New Jersey: Lawrence Erlbaum Associates, 2003, p. 259-268. 
FELIPE, T. Os processos de formação de palavra na Libras. Educação Temática Digital, Campinas, v. 7, n. 2, p. 200-217, jun, 2006.

JOHNSON, M. The body in the mind. Chicago: The University of Chicago Press, 1992. KENDON, A. Language and gesture: unity or duality? In: MCNEILL, D. (Ed.). Language and gesture. Cambridge: Cambridge University Press, 2000. p. 47-63.

LANGACKER, R. Cognitive grammar: a basic introduction. New York: Oxford University Press, 2008.

LEITE, T. A. A segmentação da língua de sinais brasileira (Libras): um estudo linguístico descritivo a partir da conversação espontânea entre surdos. 2008. 280f. Tese (Doutorado em Estudos Linguísticos e Literários em Inglês) - Faculdade de Filosofia, Letras e Ciências Humanas, Universidade São Paulo, São Paulo, 2008.

LODI, A. C. B. Uma leitura enunciativa da língua brasileira de sinais: o gênero contos de fadas. D.E.L.T.A., São Paulo, v. 20, n. 2, p. 281-310, 2004.

LIDDELL, S. K. Spatial representations in discourse: comparing spoken and signed language. Lingua. v. 98, p. 145-167, 1996.

LIDDELL, S. K. Blended spaces and deixis in sign language discourse. In: MCNEILL, D. (Ed.). Language and gesture. Cambridge: Cambridge University Press, 2000. p. 331-357.

LIDDELL, S. K. Grammar, gesture and meaning in american sign language. Cambridge: Cambridge University Press, 2003a.

LIDDELL, S. K. Sources of meaning in ASL classifiers predicates. In: EMMOREY, K. (Ed.). Perspectives on classifiers constructions in sign languages. Mahwah: Lawrence Erlbaum Associates, 2003b. p. 199-220.

MCCLEARY, L.; VIOTTI, E. Língua e gesto em línguas sinalizadas. Veredas. Juiz de Fora, v. 1, p. 289-304, 2011.

MEIER, R. P. Why different, why the same?: explaining effects and non-effects of modality upon linguistic structure in sign and speech. In: MEIER, R. P.; CORMIER, K.; QUINTO-POZOZ, D. Modalidy and structure in signed and spoken languages. New York: Cambridge University Press, 2002. p. 175-198.

PUDANS-SMITH, K. Classifiers or depiction: which should be used? ASLTA Conference: Seattle, WA, Gallaudet University, Washington, 2011. Disponível em: http://www.aslta.org/sites/default/files/images/ASLTA2011Pudans-

Smith_Depiction.pdf . Acesso em: 11 de janeiro de 2012.

QUADROS, R. M. Efeitos de modalidade de língua: as línguas de sinais. Educação Temática Digital, v. 7, n. 2, p. 168-178, 2006.

SAUSSURE, Ferdinand de. Curso de linguística geral. 6. ed. São Paulo: Cultrix, 1959. 
SCHEMBRI, A. Rethinking 'classifiers' in signed language. In: EMMOREY, K (Ed.). Perspectives on classifier constructions in sign languages. New Jersey: Lawrence Erlbaum Associates, 2003. p. 3-34.

SCHEMBRI, A.; JONES, C.; BURNHAM, D. Comparing action gestures and classifiers verbs of motion: evidence from australian sign language, taiwan sign language, and non-signer's gestures without speech. Journal of Deaf Studies and Deaf Education, Oxford, v. 10, n. 3, p. 272-290, 2005.

TAUB, S. F. Language from de body: iconicity and metaphor in american sign language. Cambridge: Cambridge University Press, 2001. 